\title{
PLANÍCIE ALUVIONAR DO RIO MOGI-GUAÇU, SP, BRASIL - AS RELAÇÕES AMBIENTAIS ENTRE O AMBIENTE AQUATICO E A ANÁLISE CLIMÁTICA BASEADA EM ASSEMBLÉIAS DE FOLHAS
}

\author{
Sueli Yoshinaga Pereira ${ }^{1}$; Fresia Ricardi-Branco ${ }^{2}$; Francisco Santiago ${ }^{3}$; Paulo Ricardo Brum \\ Pereira $^{4}$ e Fabio C. Branco 5
}

Resumo. O estudo ambiental envolveu a dinâmica do ambiente subaquático e a análise climática de morfologias de folhas em áreas selecionadas de meandros abandonados, com diferentes etapas geomorfológicas de deposição na planície fluvial do rio Mogi Guaçu. A área é uma transição do Cerrado e Mata Atlântica, bem preservada e localizada na Estação Ecológica de Mogi Guaçu (EEcMG). Em dique marginais ao rio, a floresta reflete a temperatura acuradamente, mas não a chuva, e isto pode ser explicado pela influência da água subterrânea, tipo de solo e temperatura. Nas margens internas da curvatura dos meandros, as assembleias de folhas refletem melhor as chuvas que temperatura, desde que esta última possa ser mudada pela proximidade de corpos de água (descarga de água subterrânea e proximidade do rio ou meandro).

\begin{abstract}
The environmental study involved the dynamics of subaquatic environment and climatic analysis of leaf morphologies in selected meander bends, with different geomorphological step of deposition in the Mogi Guaçu River fluvial plain located in the northeastern portion of Sao Paulo State, Brazil. The area is a transition of Cerrado (Tropical Savanna) and Mata Atlantica (Atlantic forest), well preserved and located to the Ecological Station of Mogi-Guaçu (EEcMG). At the levee, the forest reflects the temperature accurately, but not the rainfall, and it can be explained by the influence of groundwater, type of soil, and temperature. In the inner bank of meander bend, the assemblages of leaves better reflect rainfall than temperature, since the latter parameter can be changed by the proximity of water bodies (groundwater discharge and proximity to the river or meander).
\end{abstract}

Palavras-Chave - assembleia de folhas, água subterrânea, aquífero freático.

\footnotetext{
${ }^{1}$ Instituto de Geociências, UNICAMP, rua João Pandiá Calógeras 51. Campinas, SP. +55 0193521 4698. E-mail: sueliyos@ige.unicamp.br

${ }^{2}$ Instituto de Geociências, UNICAMP, rua João Pandiá Calógeras 51. Campinas, SP. +55 0193521 5119. E-mail: fresia@ige.unicamp.br

${ }^{3}$ Instituto de Geociências, UNICAMP, rua João Pandiá Calógeras 51. Campinas, SP. +55 019 3521 5119. E-mail: santiago1403@ gmail.com

${ }^{4}$ Instituto Florestal da Secretaria Estadual do Meio Ambiente. Rua do Horto 931. São Paulo, SP. +55 0112258 1811. E-mail:

paulobrumpereira@gmail.com

${ }^{5}$ Environmentality, rua Michigan 177, São Paulo, SP. E-mail: fabio.tcl@uol.com.br
} 


\section{INTRODUÇÃO}

Usualmente estudos ambientais nas áreas de preservação permanente de cursos de água abordam conhecimentos tradicionais como biologia (fauna e flora), pedologia, geomorfologia e hidrologia para sua caracterização e entendimento. No entanto, o conhecimento das condições de ocorrência das águas subterrâneas e sua interrelação com a vegetação e corpos de água superficial é tema ainda em desenvolvimento, mas alguns resultados de estudos hidrogeológicos vem contribuindo para o detalhar estes ambientes. Lautz and Siegel (2006) simulam zonas hiporréicas no entorno de macrorestos vegetais e meandros em drenagem de ambiente semiárido, e Rushton (2007) utiliza modelos matemáticos de representação regional analisando a interação rio-aquifero por efluência ou influência. Chen (2006) no rio Plate, em Nebraska, simulou a influência da vegetação ripária na dinâmica de fluxo das águas subterrâneas. Rassam et al. (2006) estudaram as zonas ripárias de dois cursos de água, sendo uma perene e outra efêmera, focando processos hidráulicos que favoreçam a remoção de nitrato e nutrientes em cursos de água de climas temperados. Alguns trabalhos estudam a variações do nível freático em áreas ripárias, como Schilling (2007) em Iowa (USA), na Inglaterra e em várias regiões da Europa (Burt et al. 2002a e b).

O entendimento atual dos processos ambientais nestas áreas contribui para a reconstrução de ambientes passados e entender os meios de preservação que atuam nas assembleias fósseis. Desta forma é essencial conhecer a dinâmica da formação e o ambiente onde estas assembléias foram depositadas e a caracterização do ambiente aquático, onde foram preservadas. Há poucos estudos sobre o tema utilizando essa abordagem. Burk et al. (2005), Burnham (1990), Gastaldo (1994), Gastaldo (2004), Gastaldo et al. (1987), Gastaldo e Staub (1999) apresentam em seus estudos tafonômicos, as características físico-químicas do meio aquático que justificam a preservação do material orgânico de origem vegetal, após sua entrada no ambiente deposicional; esses estudos focam a dinâmica de deposição de macrorestos em cursos de rios ou manguezais, sendo essas principalmente preservadas em ambientes com $\mathrm{pH}$ ácido e pouco oxidante.

O Cerrado, bioma peculiar por sua constituição de formações vegetais que variam desde campos abertos até densas florestas que podem atingir até $30 \mathrm{~m}$ de altura (Aguiar et al., 2004), destaca-se como unidade fitofisionômica pela sua grande expressividade quanto ao percentual de áreas ocupadas no Brasil, ocupando atualmente cerca de $21 \%$ do território brasileiro, o $2^{\circ}$ maior bioma do Brasil. Há poucos estudos relacionados ao desenvolvimento desse bioma durante o Cenozóico para o estado de São Paulo (Gouveia et al., 1999; Souza et al., 2013), a maioria dos trabalhos são desenvolvidos na Região do Brasil (Ribeiro and Walter, 2008; Salgado-Labouriau, 1997; Barberi et al., 2000; Ledru et al., 2001).

O presente artigo visa então contribuir para a caracterização do ambiente aquático pela integração da dinâmica da água subterrânea e os sinais sobre o clima passado. 


\section{2 ÁREA DE ESTUDO}

A área de estudo está localizada na Fazenda Campininha (Estação Ecológica de Mogi Guaçu - EEcMG), no Distrito de Martin Prado Jr., Mogi - Guaçu, São Paulo, entre as coordenadas geográficas $22^{\circ} 10^{\prime}$ e $22^{\circ} 18^{\prime}$ latitude Sul, e $47^{\circ} 08^{\prime} 47^{\circ} 11^{\prime}$ longitude Oeste (Figura 1). A porção Sul da Fazenda Campininha, onde encontra a Estação Ecológica de Mogi Guaçú (EEcMG), localiza-se a margem direita do Rio Mogi Guaçu. A bacia hidrográfica do Rio Mogi Guaçu possui uma área de $17,460 \mathrm{~km} 2$, deste, 2,650 km² encontram-se em território do Estado de Minas Gerais e 14,653km² em território do Estado de São Paulo. Na bacia hidrográfica do rio Mogi Guaçu, a temperatura média anual varia de $20.5^{\circ} \mathrm{C}$ a $22.5^{\circ} \mathrm{C}$, a média anual de precipitação varia de 1.400 a $1.600 \mathrm{~mm}$. Na estação chuvosa (Outubro a Março) a precipitação acumulada varia de 1.100 a $1.250 \mathrm{~mm}$, e na estação seca (Abril a Setembro) de 250 a 300 mm (CBH-Mogi 1999).

A área de estudo situa-se entre a zona de transição dos biomas Cerrado e Mata Atlântica e possui características de ambos. As principais formações ou tipos de vegetação encontradas na área de estudo são da Mata Atlântica, Bioma Cerrado e Floresta aluvial semidecídua (Mata Ripária) e Campo Úmido, compreendendo planícies de inundação e pântanos (Eiten 1963). As áreas úmidas (Florestas Ripárias) estão localizadas na área de transição da floresta e os cursos de água (Eiten 1963; Pinto et al. 1997). Duas áreas de Campo Úmido foram delimitadas na área de estudo.

\section{CONTEXTO GEOLÓGICO}

A área de estudo está dentro da Bacia do Paraná (Perrotta et al., 2005), que se caracteriza pela acumulação de rochas sedimentares, localizado ao longo das margens do rio Mogi - Guaçú e alguns de seus principais afluentes. A bacia é considerada a província hidrogeológica mais importante no Brasil, com cerca de $45 \%$ das reservas de água subterrânea do país. Na área de estudo, a Bacia do Paraná é representado por rochas de idades Permiano e Jurássico. Assim, os estratos do Permiano pertencem aos grupos de Itararé, Guatá e Passa Dois. As rochas da Formação Serra Geral são sobrepostos a anterior (Perrotta et al., 2005), e representam o vazamento de lava durante o jurássico como o resultado do rifting que separava a África da América do Sul. Finalmente, os depósitos aluviais cenozóicos são encontrados predominantemente em EEcMG nas margens do Mogi Guaçu, e ocupando cerca de $68,5 \%$ do EEcMG. 


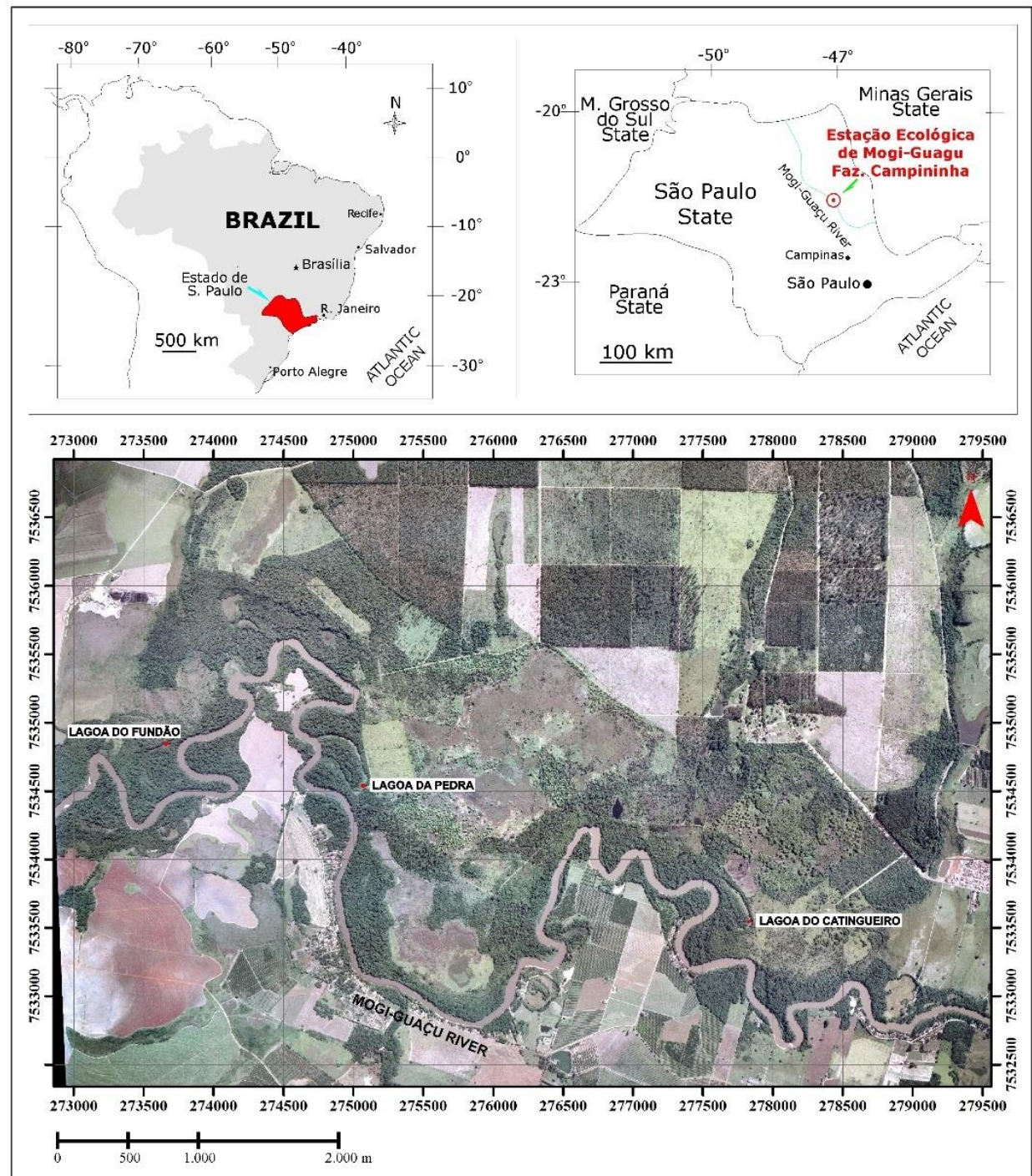

Figura 1 - Mapa de Localização da Fazenda Campininha (EEcMG) e dos pontos estudados.

\section{HIDROLOGIA E HIDROGEOLOGIA}

EEcMG (Estação Ecológica de Mogi Guaçu) está localizada na Unidade de Gerenciamento de Recursos Hídricos do Mogi-Guaçu-UGRHI 9 (Unidade de Gerenciamento de Recursos Hídricos de Mogi Guaçu. Os municípios de Mogi-Guaçu, Conchal e Araras pertencem à região do Alto Mogi, juntamente com os municípios de Engenheiro Coelho, Espírito Santo do Pinhal, Estiva Gerbi, Leme, Mogi Mirim, Pirassununga, Porto Ferreira, e Santa Cruz da Conceição (CBH-Mogi 1999).

A área de estudo situa-se perto da estação fluviométrica 3D-004, e a vazão média do rio Mogi Guaçu situa-se entre 30 e $125 \mathrm{~m}^{3} / \mathrm{s}$. Em relação à hidrogeologia, os principais aquíferos da área de estudo são as rochas indiferenciadas do Cenozoico, o Itararé (Tubarão) e Cristalino Fraturado (CBH-Mogi 1999). As coberturas cenozoicas indiferenciadas são caracterizadas por variáveis granulação areias, argilas e cascalhos de Itaqueri, Rio Claro e formações de São Paulo. Os 
sedimentos aluviais são abrangidos pelo aquífero, com caracterização mais regional. O Tubarão Aquífero (Grupo Itararé) mostra depósitos de arenitos, siltitos, diamictitos, ritmitos e mistitos do Carbonífero a Permiano. Apresenta extensão regional, é descontínuo, e sua espessura pode chegar a 100 metros. A produtividade dos poços profundos tem uma média de fluxo de $7 \mathrm{~m}^{3} / \mathrm{h}$, de uma banda que varia de 3 a $30 \mathrm{~m}^{3} / \mathrm{h}$. O Cristalino (rochas pré-cambrianas) é composta por granitos, gnaisses, migmatitos, filitos, xistos, quartzitos e metassedimentos. É descontínua, porque a produtividade está relacionada com fraturas dos existentes, e a intensidade / desgaste, e a sua produtividade é entre 2 e $40 \mathrm{~m}^{3} / \mathrm{h}$, com uma média de $5 \mathrm{~m}^{3} / \mathrm{h}$.

\section{MÉTODO}

\subsection{Estudos Hidrogeológicos}

Na caracterização do ambiente das águas subterrâneas 15 sondagens foram executadas, na Ilha da Pedra; durante a perfuração amostras do material inconsolidado foram coletados para descrição visual e análise granulométrica. Nessas sondagens foram instalados 15 poços de monitoramento, com 2 polegadas de diâmetro de revestimento perfurados em furos com seis polegadas de diâmetro. O material de revestimento e filtro consistiu de PVC branco, com filtro com abertura de $0,25 \mathrm{~mm}$. O redor dos filtros foi preenchido por pré-filtro (areia grossa) e selados com bentonita. A profundidade de perfuração variou de acordo com a profundidade do nível freático encontrado. Na Ilha da Pedra 15 poços foram construidos, sendo 4 multiníveis (com duas profundidades). Os poços mais profundos foram instalados em média 4 metros abaixo do poço mais raso. A localização e identificação dos poços encontram-se na tabela 1.

Tabela 1 - Localização e profundidade dos poços de monitoramento construídos na Ilha da Pedra.

\begin{tabular}{cccc|cccc}
\hline $\begin{array}{c}\text { Poço de } \\
\text { Monitoramento }\end{array}$ & UTM E & UTMN & $\begin{array}{c}\text { Profundidade } \\
(\mathrm{m})\end{array}$ & $\begin{array}{c}\text { Poço de } \\
\text { Monitoramento }\end{array}$ & UTM E & UTMN & $\begin{array}{c}\text { Profundidade } \\
(\mathrm{m})\end{array}$ \\
\hline IF 2 & 274836 & 7535737 & 14,32 & IF 12 & 274913 & 7535735 & 15,76 \\
IF 3 & 274830 & 7535739 & 14,67 & IF 13d & 274942 & 7535725 & 19,61 \\
IF 6 & 274865 & 7535735 & 15,27 & IF 13s & & & 15,30 \\
IF 7 & 274864 & 7535743 & 15,37 & IF 14 & 274960 & 7535692 & 14,90 \\
IF 8 & 274901 & 7535794 & 14,07 & IF 15 & 274990 & 7535701 & 12,16 \\
IF 9d & 274917 & 7535775 & 16,28 & IF 16 & 275025 & 7535695 & 10,48 \\
IF 9s & & & 12,31 & IF 17d & 275054 & 7535690 & 12,60 \\
IF 10 & 274940 & 7535787 & 13,63 & IF 17s & & & 7,91 \\
IF 11d & & & 13,39 & IF 18 & 275085 & 7535695 & 7,00 \\
IF 11s & 274973 & 7535809 & 10,45 & & & & \\
\cline { 5 - 6 } & & & &
\end{tabular}


Na Lagoa da Ilha, a profundidade dos poços variou de 7,00 a 15,75 metros (mais rasos) e entre 12,60 a 19,61 metros (mais profundos). As profundidades dos poços variaram entre 7,00 a 19,61 metros, sendo 4 poços multiníveis, para analisar o comportamento do fluxo vertical da água subterrânea, já que a planície.

A determinação da condutividade hidráulica $(K)$ foi obtido por meio dos ensaios de slugs testes. O método de cálculo de K utilizado foi Hvorslev (1951).

O monitoramento dos níveis de água foi realizado fevereiro de 2012, maio de 2012. As amostragens de água subterrânea para análise físico-química foram realizadas no mês de maio de 2012. No dia anterior a coleta foi realizada o esgotamento dos poços para remoção da água estagnada. A coleta foi feita por bailer e a amostra em seguida sofreu filtragem por filtro de 0,22 $\mu \mathrm{m}$; amostrou-se $40 \mathrm{~mL}$ de água para análise por cromatografia de íons, o mesmo volume para análise por ICP-MS com acidificação da amostra por $\mathrm{HNO}_{3}$, e $400 \mathrm{~mL}$ para análise da alcalinidade. Coleta do branco (água deionizada) foi utilizada com os mesmos métodos de amostragem como parâmetro de qualidade analítica. Todas as amostras foram refrigeradas a $4^{\circ} \mathrm{C}$. Por fim foi feita a medição de parâmetros de campo (pH, ORP, E.C. e temperatura) por equipamento portátil.

As amostras coletadas foram analisadas no Laboratório de Geoquímica Analítica (Instituto de Geociências/Unicamp) para a determinação de constituintes maiores por meio de cromatografia de íons, alcalinidade por meio de titulação e demais elementos através de ICP-MS (Espectrometria de Massa com Plasma Indutivamente Acoplado).

\subsection{Análises climáticas da morfologia das folhas}

Amostragem de camadas de folhas - Sete conjuntos de folhas foram coletadas dentro de uma área de 1,5 x 1,5 m (Burnham, 1994), divididos em três locais específicos conhecidos como Catingueiro, Ilha da Pedra e Fundão, que representam três diferentes estágios de evolução de lagos que se forma na curva de meandro (Oxbow lakes) - Catingueiro como o mais novo, Pedra-Ilha o intermediário, e Fundão o mais avançado. Fora dos sete conjuntos, quatro foram listados em áreas em diques marginais sob um dossel de Cerrado, e três relacionados com os bancos internos de curvas dos meandros sob um dossel de mata ciliar, e associado aos locais já mencionados (Catingueiro, Pedra-Ilha e Fundão). As folhas foram prensadas e recolhidas para evitar a deterioração. No laboratório que foram classificadas em tipos morfológicos de acordo com a Ellis et al. (2009) e Denver Museum of Nature and Science (2011).

Fisionomia Foliar - Análise Margem Foliar (LMA) - Foram avaliadas cinco equações que usam o princípio do LMA para o cálculo de MAT. As duas primeiras propostas por Wilf (1997) (Tabela 3), e com base em CLAMP (Climate Leaf Analysis Multivariate Program; Wolfe 1993) 
dados. Essas equações incluem locais no Hemisfério Norte, principalmente, e ambos foram recomendados pelo Kowalski (2002) para o cálculo MAT de floras com altas temperaturas e baixa altitude nas regiões tropicais da América do Sul. Hinojosa et ai. (2011) propôs as três seguintes equações. A primeira (Tabela 2) foi gerado a partir da base de dados de CLAMP (http://www.open.ac.uk/earth-research/spicer/CLAMP/ Clampset1.html, que também inclui locais na América do Norte, América Central e Japão. A segunda e terceira equações usou dados de floras tropicais e sul da América do Sul.

Tabela 2 Equações com base na Análise Margem Foliar (LMA) e Área de Análise de Folha (LAA) utilizado para a estimativa da temperatura média anual e precipitação média anual. Legenda: ${ }^{\text {a }}$ série de sites. ${ }^{b}$ erros padrão do modelo. ${ }^{c}$ coeficientes de determinação. ${ }^{d}$ valor estatístico calculado. eproporção de espécies inteiras em margens. ${ }^{\mathrm{f}} \mathrm{M} \ln \mathrm{A}$, é a área foliar média de todas as outras espécies floridas calculada de acordo com Wilf et al. (1998), onde MlnA $=\Sigma \mathrm{a}_{\mathrm{i}} \mathrm{p}_{\mathrm{i}}$, e $\mathrm{a}_{\mathrm{i}}$ representa as sete médias das áreas de log naturais das classes de tamanho de Raunkiaer (1934), modificado pelo Webb (1959), e p prepresenta a proporção de espécies de cada classe de tamanho

\begin{tabular}{|c|c|c|c|c|c|}
\hline LMA- número da equação e fonte & Equação & $\mathbf{n}^{\mathrm{a}}$ & $\mathbf{S E}^{\mathrm{b}}\left({ }^{\circ} \mathbf{C}\right)$ & $R^{2 \mathrm{c}}$ & $p$-value ${ }^{\mathrm{d}}$ \\
\hline Eq. 1 - Wilf (1997) & $\mathrm{MAT}=29.10(E)^{\mathrm{e}}-0.266$ & 106 & 3.4 & 0.760 & $<0.0005$ \\
\hline Eq. 2 - Wilf (1997) & $\mathrm{MAT}=24.40 E+3.250$ & 74 & 2.1 & 0.840 & $<0.0005$ \\
\hline Eq. 3 -Hinojosa et al. (2011) & $\mathrm{MAT}=25.00 E+3.420$ & 144 & 2.2 & 0.870 & $<0.0001$ \\
\hline Eq. 4 - Hinojosa et al. (2011) & $\mathrm{MAT}=23.42 E+3.600$ & 44 & 3.5 & 0.480 & $<0.0001$ \\
\hline Eq. 5- Hinojosa et al. (2011) & $\mathrm{MAT}=26.03 E+1.310$ & 74 & 2.8 & 0.820 & $<0.0001$ \\
\hline LAA- número da equação e fonte & Equação & $\mathbf{n}$ & $\mathrm{SE}(\mathrm{mm})$ & $R^{2}$ & $p$-value \\
\hline Eq. 6 - Wilf et al. (1998) & $\ln M A P=0.548(M \ln A)^{f}+0.768$ & 50 & $0.359(\ln )$ & 0.760 & $<0.01$ \\
\hline Eq. 7 - Jacobs and Herendeen (2004) & $\ln \mathrm{MAP}=2.566+0.309 \mathrm{M} \ln \mathrm{A}$ & 42 & 39 & 0.734 & $<0.001$ \\
\hline
\end{tabular}

Análise de área foliar (LAA) - Duas equações (Tabela 3) foram utilizados para estimar o MAP. A primeira proposta por Wilf et al. (1998), baseado em 50 florestas modernas em África e na América Central. Assim, cobrindo uma ampla variedade de diferentes tipos de plantas e climas. Jacobs e Herendeen (2004) propuseram a segunda equação com base em dados de 42 locais de clima tropical na África e na Bolívia.

Clima Programa Folha Análise Multivariada (CLAMP) - A ferramenta utilizada foi CLAMP Online (http://clamp.ibcas.ac.cn/), que realizou duas análises usando o conjunto de Physg3brcAZ data - a primeira com dados climáticos Met3brAZ e o segundo com GRIDMet3brcAZ quadrado de Dados Climáticos (http: // www.open.ac.uk/earth-research/spicer/CLAMP/Clampset1.html). 


\section{RESULTADOS}

\subsection{Hidrogeologia}

Os aquíferos estudados são rasos e livres, de porosidade primária e de origem aluvionar; a área (Ilha do Fundão) corta meandros ativos e abandonados, e estão próximos ao rio Mogi Guaçu.

Os ensaios de granulometria indicaram uma variação da textura dos sedimentos, porém com predominância da areia e pouco silte. No geral, estes sedimentos variaram areia argilosa - argila arenosa - argila, na Ilha do Fundão.

Na Ilha do Fundão, os sedimentos são arenosos, com alta porcentagem da fração areia (em geral acima de $40 \%$ ), com maior variação textural. A argila apresenta melhor distribuição (entre 10 a $80 \%$ ), com a maior parte das amostras de solo entre 10 e 60\%. Assim como no Catingueiro, a porcentagem de silte é baixa e varia entre 0 a $20 \%$. Há ocorrências de maior porcentagem de argila e silte nas porções mais superficiais, principalmente nas proximidades da lagoa.

O perfil IF 3 (oeste) - IF 6 - IF 7 - IF 8 - IF 9 - IF 10 - IF 11 (nordeste) apresenta a distribuição vertical das frações; há um decréscimo da fração areia e consequente aumento da fração argila na porção leste do perfil (Figura 2). No perfil IF 12 (oeste) - IF 14 - IF 16 - IF 15 - IF 16 IF 17 - IF 18 (leste), já existe uma distribuição das frações mais finas ao longo desse perfil, na porção leste (Figura 3). Com exceção do IF 12, os demais pontos apresentam frações mais finas (argila principalmente) nas porções mais superficiais do perfil. Há uma grande concentração de areia em profundidade em direção ao corpo de água e rio. Esta concentração aumenta com a profundidade.
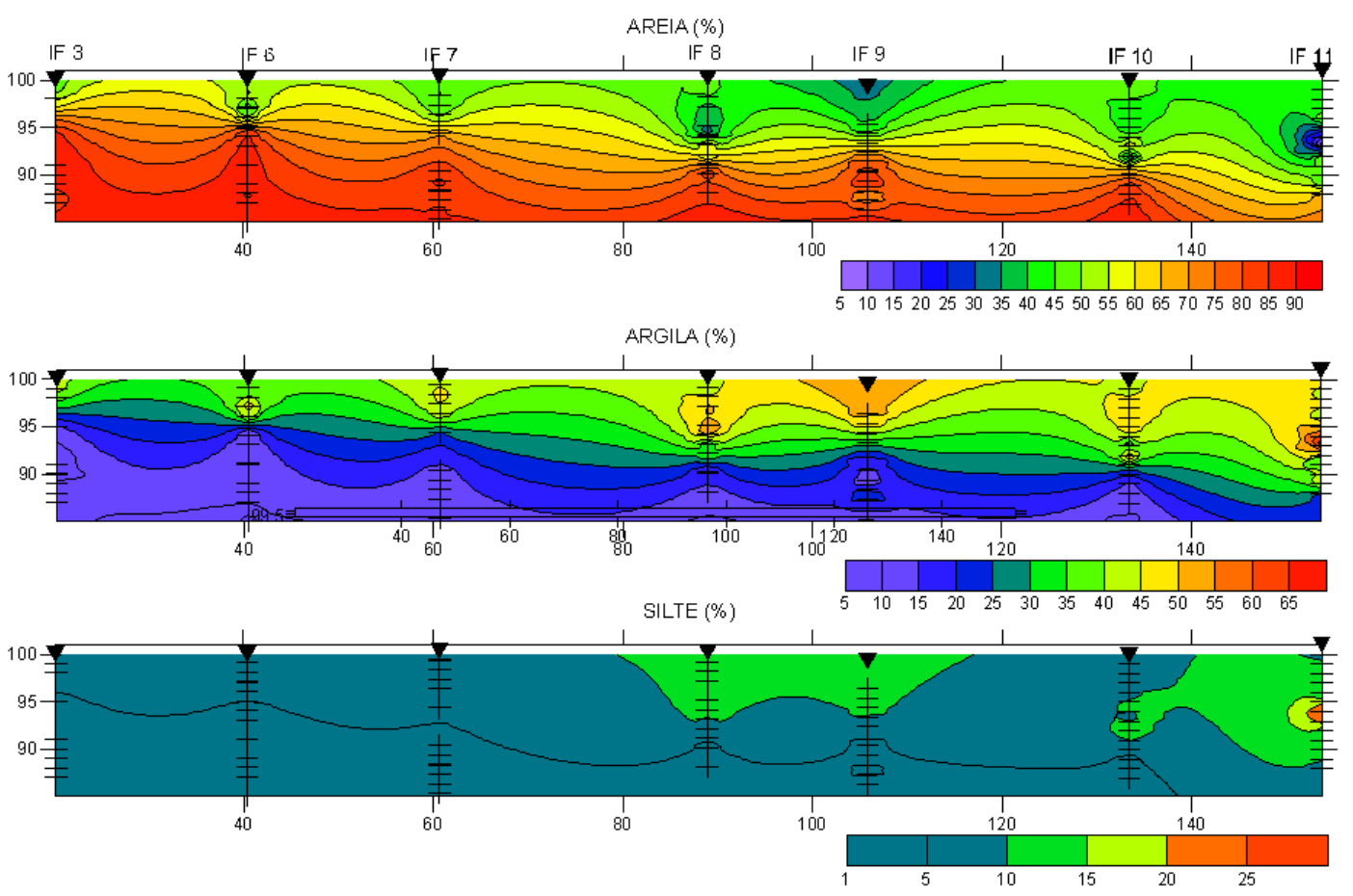
Figura 2 - Distribuição da granulometria (areia, argila e silte) ao longo do perfil oeste da Ilha do Fundão
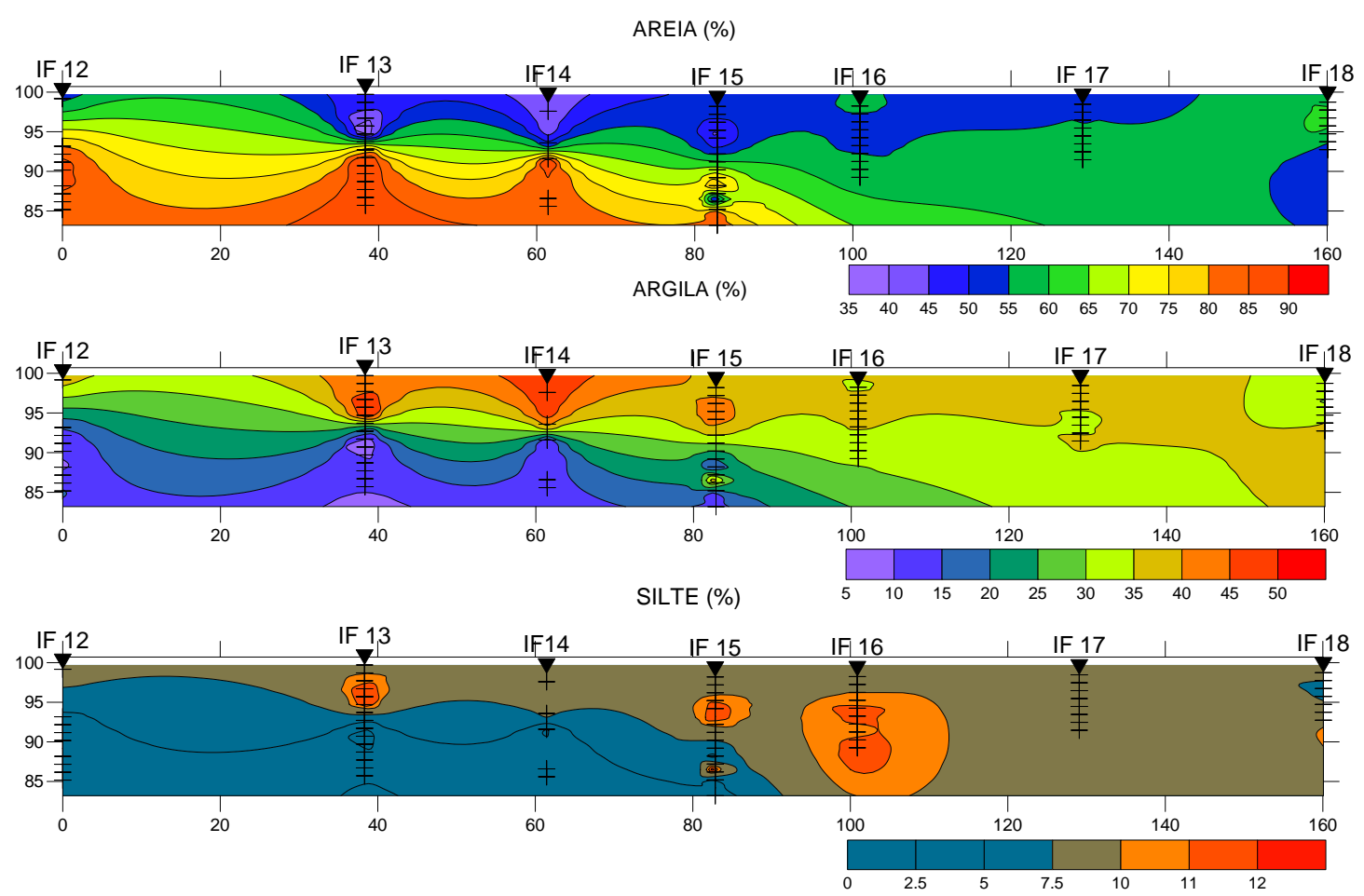

Figura 3 - Distribuição da granulometria (areia, argila e silte) ao longo do perfil leste da Ilha do Fundão
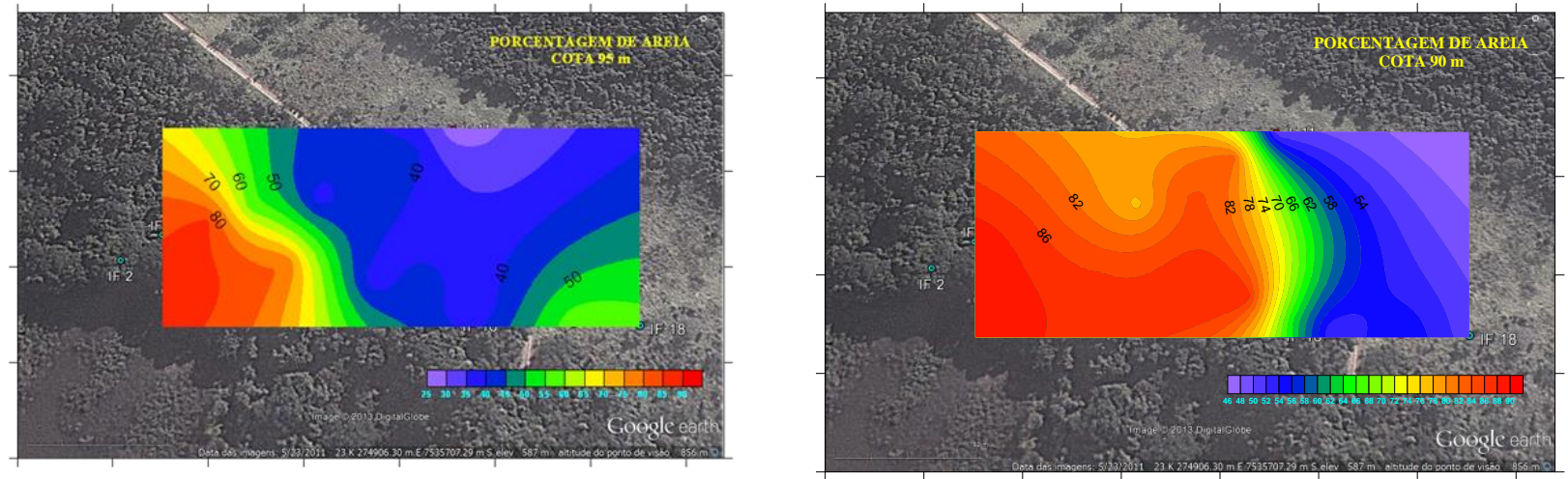

Figura 4 - Distribuição média da areia dos sedimentos em profundidade (cota 95m e cota 90m)

Em planta (Figura 5) a distribuição da areia dos sedimentos aumenta em direção aos corpos de água (lago e rio) e se expande em profundidade.

Os valores de Condutividade Hidráulica $(\mathrm{K})$ do aquífero variaram de $1,03 \times 10^{-1} \mathrm{~cm} / \mathrm{s}$ a 3,83 x $10^{-3} \mathrm{~cm} / \mathrm{s}$ (aquífero raso), média de $5,9 \times 10^{-3} \mathrm{~cm} / \mathrm{s}$ (aquífero profundo) na Ilha do Fundão e 5,8 x $10^{-3} \mathrm{~cm} / \mathrm{s}$ a $2,1 \times 10^{-1} \mathrm{~cm} / \mathrm{s}$ no Catingueiro, conforme Tabela 3 . Os valores de $\mathrm{K}$ indicam um aquifero de alta permeabilidade, e presença de areias bem selecionada a areia finas e siltosas. Destaca-se também presença de cascalhos em alguns poços. 
Tabela 3 - Valores de Condutividade Hidráulica dos aquíferos na Ilha do Fundão

\begin{tabular}{cccc}
\hline \multicolumn{4}{c}{ ILHA DO FUNDÃO } \\
KOÇO $(\mathrm{cm} / \mathrm{s})$ & POÇO & $\mathrm{K}(\mathrm{cm} / \mathrm{s})$ \\
\hline IF 2 & $2,65 \times 10^{-2}$ & IF 11 raso & $3,78 \times 10^{-2}$ \\
IF 6 & $3,83 \times 10^{-3}$ & IF 17 raso & $4,49 \times 10^{-2}$ \\
IF 8 & $9,68 \times 10^{-2}$ & IF 13 fundo & $6,82 \times 10^{-3}$ \\
IF 9 fundo & $5,00 \times 10^{-3}$ & IF 13 raso & $2,58 \times 10^{-2}$ \\
IF 9 raso & $1,03 \times 10^{-1}$ & & \\
\hline
\end{tabular}

Os mapas potenciométricos foram construídos baseados na campanha de monitoramento que representasse o período mais chuvoso (ou quando os níveis de água estivessem mais rasos), a situação do período de amostragem para análise físico-química, e o período mais seco (ou quando os níveis de água estivessem mais profundos). Os mapas apresentam a situação da potenciometria em janeiro de 2012 e maio de 2012. Na Ilha do Fundão, os mapas potenciométricos apresentam as situações de janeiro de 2012 e maio de 2012 (Figura 5). Os mapas representativos do aquífero raso mostram a direção de fluxo em direção ao corpo de água (lago) tanto no período chuvoso quanto no seco, mostrando comportamento efluente (a água subterrânea descarregando no lago). No período mais chuvoso (janeiro de 2012) as linhas equipotenciais mais elevadas e mais concentradas mostram maiores cargas hidráulicas e maiores gradientes hidráulicos, indicando uma dinâmica maior no aquífero, e maior descarga de água no corpo de água. Em maio de 2012, os sentidos de fluxo das águas subterrâneas se mudam sutilmente na porção norte da área, porém descarregando no corpo de água (situado a sudoeste da área).
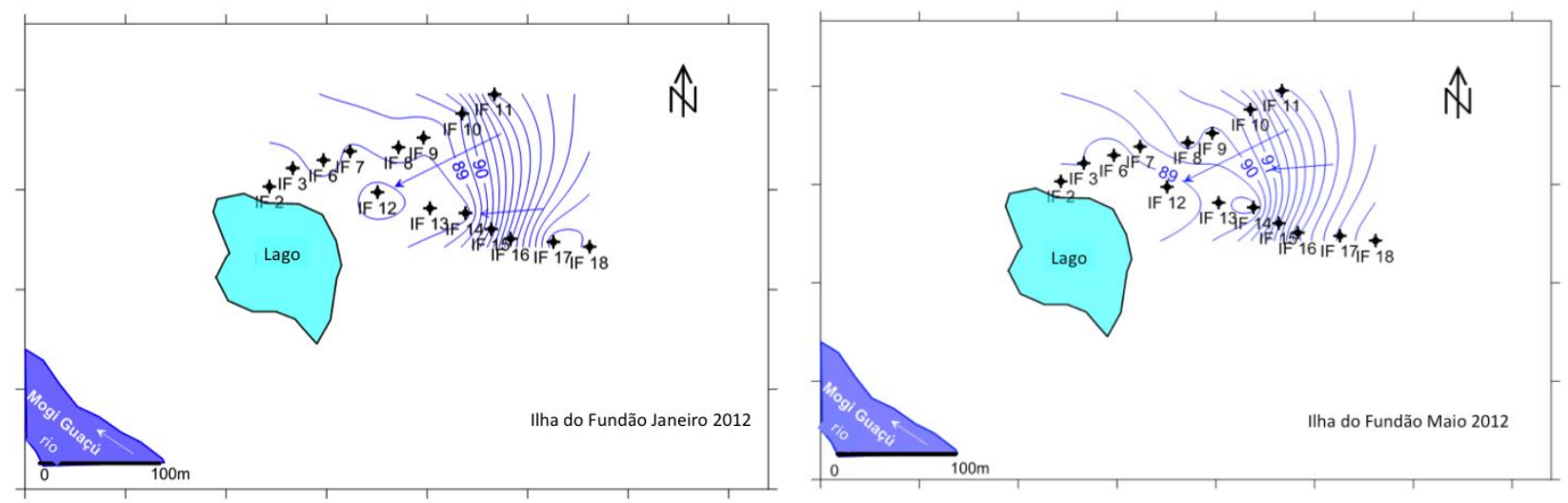

Figura 5 - Mapas potenciométricos na Ilha do Fundão, representativos de Janeiro de 2012 (mês chuvoso) e Maio de 2012 (mês seco) 
$\mathrm{Na}$ porção mais profunda do aquifero, a potenciometria foi analisada para os mesmos períodos. A Figura 6 apresentam uma variação significativa durante os meses monitorados. Em janeiro de 2012, os níveis estavam rasos e a potenciometria apresentava gradientes hidráulicos maiores e direção predominante leste - oeste. Em maio de 2012 o gradiente hidráulico torna-se menor e com o mesmo sentido defluxo.
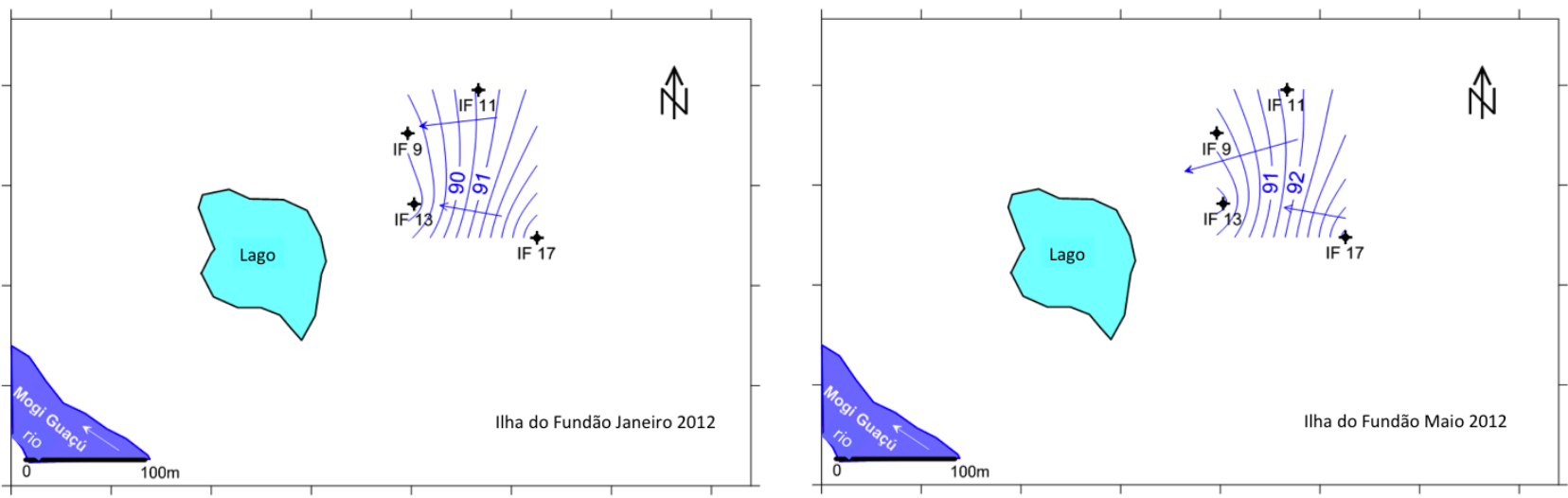

Figura 6 - Mapas potenciométricos na porção mais profunda do aquífero, representativos de Janeiro 2012 (mês chuvoso) e Maio 2012 (mês seco).

As águas de poços mais rasos apresentaram-se ácidas e oxidantes, com $\mathrm{pH}$ variando entre 5.20 a 6.94 e com Eh $(\mathrm{mV})$ entre 242 e $478 \mathrm{mV}$. Os baixos valores de Condutividade Elétrica (E.C.), entre 8.3 a $28.2 \mu \mathrm{S} / \mathrm{cm}$, indicam águas com baixa mineralização. A temperatura das águas apresentou-se entre 21,2 a $21,9^{\circ} \mathrm{C}$. A concentração de bicarbonato variou de 4.2 a 49.0 mg.L $\mathrm{L}^{-1}$. As amostras de águas subterrâneas dos poços IF 11d e IF17d (mais profundos) apresentaram-se diferenciadas dos demais, com maior mineralização (E.C. 146.2 and $402.0 \mu \mathrm{S}_{\mathrm{cm}} \mathrm{cm}^{-1}$ ), pH neutro $(6.94$ and 7,42) e Eh de menores valores $(381$ and $300 \mathrm{mV})$. A temperatura das águas variou de 20,5 a $22,7^{\circ} \mathrm{C}$ e o bicarbonato apresentou os valores de 94 e $282 \mathrm{mg} . \mathrm{L}^{-1}$.

As águas possuem baixa concentração de elementos químicos, com baixas concentrações de cloreto (entre 50 a $910 \mu \mathrm{g} . \mathrm{L}^{-1}$ ), sulfato (entre $<10$ a 4,640 $\mu \mathrm{g} . \mathrm{L}^{-1}$ ), $\mathrm{NO}_{3}{ }^{-} \mathrm{N}$ (entre $<3$ a $160 \mu \mathrm{g} . \mathrm{L}^{-1}$ ), cálcio (entre 55 e 44,280 $\mu \mathrm{g} . \mathrm{L}^{-1}$ ), sódio (entre 50 a 61,600 $\mu \mathrm{g} . \mathrm{L}^{-1}$ ), amônio (entre <20 a $60 \mu \mathrm{g} . \mathrm{L}^{-1}$ ) e potássio (entre 40 a 1,180 $\mu \mathrm{g} \cdot \mathrm{L}^{-1}$ ). O íon fluoreto ocorreu somente nas águas do poço IF17d. As águas subterrâneas mais profundas são as possuidoras de maiores concentrações de elementos maiores. Na Ilha do Fundão, a baixa mineralização das águas, pH ácido e ambiente oxidante podem caracterizar as águas subterrâneas local. A parte menos profunda deste aquífero pode indicar águas com baixo tempo de residência, sujeita a recarga das águas sazonais. No entanto foram observadas águas mais mineralizadas nos poços mais profundos, já indicando um tempo maior de residência e de contato com o aquífero. As águas subterrâneas são predominantemente bicarbonatadas cálcicas. 


\subsection{Análise climática de morfologias foliares}

O número de folhas analisadas em cada conjunto variou entre 293 e 771 espécimes e o numero de morfotipos identificados entre 15 e 31 (Tabela 4). A relação entre o número de espécimes e de morfotipos foi muito variável, a exceção dos valores obtidos para o Catingueiro (Tabela 4). As coleções também foram organizadas de acordo com a posição geomorfológica na qual foram coletadas (dique marginal e nas margens internas das curvas de meandro) para obter um número maior de morfotipos e o resultado mostrou que em ambas situações geomorfológicas existe uma proporção muito semelhante entre numero de espécimes por morfotipos (Tabela 4).

Tabela 4 - Estimativa da temperatura média anual e precipitação média anual de amostras de serapilheira dos locais Catingueiro (C-C'), Ilha ( $\left.\mathrm{I}_{1}-\mathrm{I}_{2}-\mathrm{I}_{2}{ }^{\prime}\right)$ e Lagoa do Fundão (LF-LF') na EEcMG utilizando Leaf Margin Analysis (LMA), Leaf Area Analysis (LAA) e duas diferentes conjuntos de dados de calibração CLAMP (Ungridded Physg3brcAz e Gridded Physg3brcAZ).

\begin{tabular}{|c|c|c|c|c|c|c|c|c|c|c|c|c|c|c|c|}
\hline \multirow{2}{*}{ Local } & \multirow{2}{*}{$\mathbf{S}^{\mathrm{a}}$} & \multirow{2}{*}{$\mathbf{m}^{\mathrm{b}}$} & \multirow{2}{*}{$\mathbf{S}: \mathbf{m}^{\mathrm{c}}$} & \multirow{2}{*}{$\mathbf{E}^{\mathrm{d}}$} & \multicolumn{5}{|c|}{ LMA - MAT $\left({ }^{\circ} \mathbf{C}\right)$} & \multicolumn{2}{|c|}{$\begin{array}{c}\text { CLAMP - MAT } \\
\left({ }^{\circ} \mathrm{C}\right)\end{array}$} & \multicolumn{2}{|c|}{$\begin{array}{l}\text { LAA - MAP } \\
\quad(\mathbf{m m})\end{array}$} & \multicolumn{2}{|c|}{$\begin{array}{l}\text { CLAMP - MAP } \\
(\mathbf{m m})\end{array}$} \\
\hline & & & & & $\begin{array}{c}\text { Eq. } \\
1\end{array}$ & $\begin{array}{c}\text { Eq. } \\
\mathbf{2}\end{array}$ & $\begin{array}{c}\text { Eq. } \\
\mathbf{3}\end{array}$ & $\begin{array}{c}\text { Eq. } \\
4\end{array}$ & $\begin{array}{c}\text { Eq. } \\
5\end{array}$ & Ungridded & Gridded & Eq. 6 & Eq. 7 & Ungridded & Gridded \\
\hline \multicolumn{16}{|l|}{7} \\
\hline $\mathrm{C}$ & 771 & 18 & $42.8: 1$ & 66.7 & 19.1 & 19.5 & 19.9 & 19.2 & 18.7 & 20.5 & 19.5 & 1179 & 1240 & 2063 & 1897 \\
\hline $\mathbf{I}_{1}$ & 485 & 16 & $30.3: 1$ & 87.5 & 25.2 & 24.6 & 25.1 & 24.1 & 24.1 & 29.1 & 26.7 & 1560 & 1455 & 3557 & 3290 \\
\hline $\mathbf{I}_{2}$ & 454 & 31 & 14.6:1 & 93.5 & 26.9 & 26.1 & 26.6 & 25.5 & 25.7 & 23.6 & 21.9 & 1025 & 1133 & 2587 & 2312 \\
\hline $\mathbf{L F}$ & 293 & 16 & $18.3: 1$ & 68.7 & 19.7 & 20.0 & 20.4 & 19.7 & 19.2 & 24.6 & 23.6 & 1343 & 1343 & 2484 & 2572 \\
\hline \multirow[t]{2}{*}{ EEcMG } & 2003 & 61 & $32.8: 1$ & 82 & 23.6 & 23.3 & 23.7 & 22.8 & 22.7 & 24.1 & 22.7 & 1252 & 1277 & 2580 & 2437 \\
\hline & \multicolumn{4}{|c|}{ Erros médios absolutos } & 2.4 & 2.2 & 2.7 & $\underline{1.8}$ & $\underline{1.6}$ & 3.9 & 2.4 & -66 & $\underline{-49}$ & 1319 & 1166 \\
\hline \multicolumn{16}{|c|}{ Margens internas de curvas de meandros } \\
\hline $\mathbf{C}^{\prime}$ & 649 & 15 & $43.2: 1$ & 80.0 & 23.0 & 22.8 & 23.2 & 22.0 & 22.1 & 21.4 & 19.5 & 1179 & 1240 & 2688 & 2263 \\
\hline $\mathbf{I}_{2}{ }^{\prime}$ & 528 & 27 & $19.5: 1$ & 77.8 & 22.4 & 22.2 & 22.7 & 21.8 & 21.6 & 24.5 & 22.7 & 1514 & 1426 & 2682 & 2546 \\
\hline LF' & 399 & 17 & $23.5: 1$ & 88.2 & 25.4 & 24.8 & 25.3 & 24.3 & 24.3 & 26.2 & 24.1 & 1240 & 1277 & 3350 & 2910 \\
\hline EEcMG' & 1576 & 47 & $33.5: 1$ & 80.8 & 23.2 & 23.0 & 23.4 & 22.5 & 22.3 & 24.7 & 22.8 & 1316 & 1316 & 2895 & 2646 \\
\hline \multicolumn{5}{|c|}{ Erros médios absolutos } & 3 & 2.7 & 3.1 & $\underline{2.1}$ & $\underline{2}$ & 3.7 & 1.8 & -23 & $\underline{-20}$ & 1569 & 1256 \\
\hline
\end{tabular}

Temperatura média real baseado em registro na $\mathrm{EEcMG}=20.5^{\circ} \mathrm{C}$

Precipitação média anual baseada em registro na EEcMG $=1335 \mathrm{~mm}$

\footnotetext{
${ }^{\mathrm{a}}$ Número de espécimes por amostra.

${ }^{\mathrm{b}}$ Morfotipos de folha (assumido ser espécies).

${ }^{\mathrm{c}}$ Relação de tamanho da amostra e número de espécies recuperadas

${ }^{\mathrm{d}}$ Proportion of entire-margined species.
} 
$\mathrm{Na}$ Tabela 4 e na Figura 7 foram resumidas as estimativas para a MAT obtidas dos conjuntos de folhas coletados e da combinação dos dados de cada um dos ambientes selecionados, fato que permitiu maximizar o número de espécimes e de morfotipos. As amostras coletadas nos diques marginais do rio refletem melhor a temperatura que as assembleias de folhas coletadas próximas aos margem interna das curvas de meandros refletem melhor as estimativas de temperatura com base nas equações no LMA (Tabela 4, Figura 7). Nos depósitos de dique marginal de rio o erro médio é de $1.6-2.7{ }^{\circ} \mathrm{C}$ e depósitos associados as curvas de meandros é de $2-3.1{ }^{\circ} \mathrm{C}$, considerando ás equações Eq. 4 e Eq 5 como as mais precisas (Tabela 4). Com relação à estimativa da temperatura associada aos conjuntos de dados do CLAMP, é possível observar que os resultados mais próximos a realidade foram os obtidos nas assembleias associadas as margens internas das curvas de meandro. Dessa forma o erro oscilou entre $1.8-3.7{ }^{\circ} \mathrm{C}$ para as últimas e entre $2.4-3.9{ }^{\circ} \mathrm{C}$ para as assembleias coletadas nos diques marginais de rio (Tabela 4, Figura 7).

Nas Tabela 4 e Figura 8 foram resumidas as estimativas da MAP para os conjuntos estudados e a combinação deles segundo a sua posição geomorfologia (dique marginal de rio e banca interna de curvaturas de meandro). Os valores da MAP utilizando LAA (Eq. 6 e Eq. 7), para todas as assembleias são muito consistentes e muito mais baixos que aqueles derivados por conjuntos de dados da calibração CLAMP utilizados (Tabela 4, Figura 8). Assim, o conjunto de dados Gridded relacionado aos depósitos de dique marginal de rio é o que gerou um resultado mais condizente com a MAP atual.

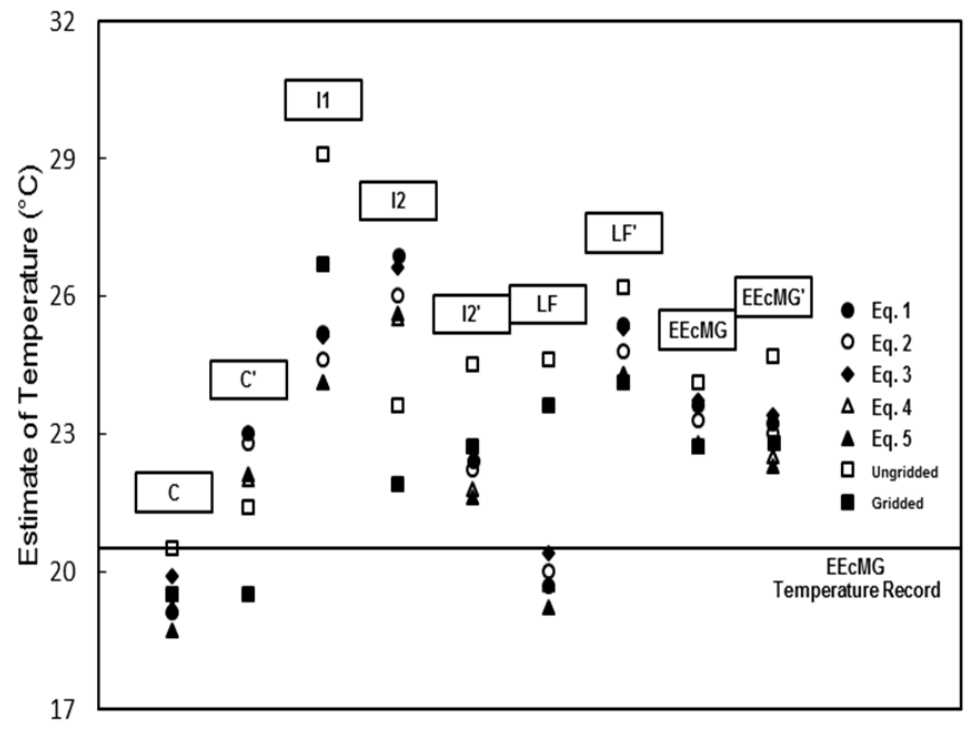

Figura 7 - Estimativas de temperatura para a MAT, obtidas dos conjuntos de folhas coletados e da combinação dos dados de cada um dos ambientes selecionados 


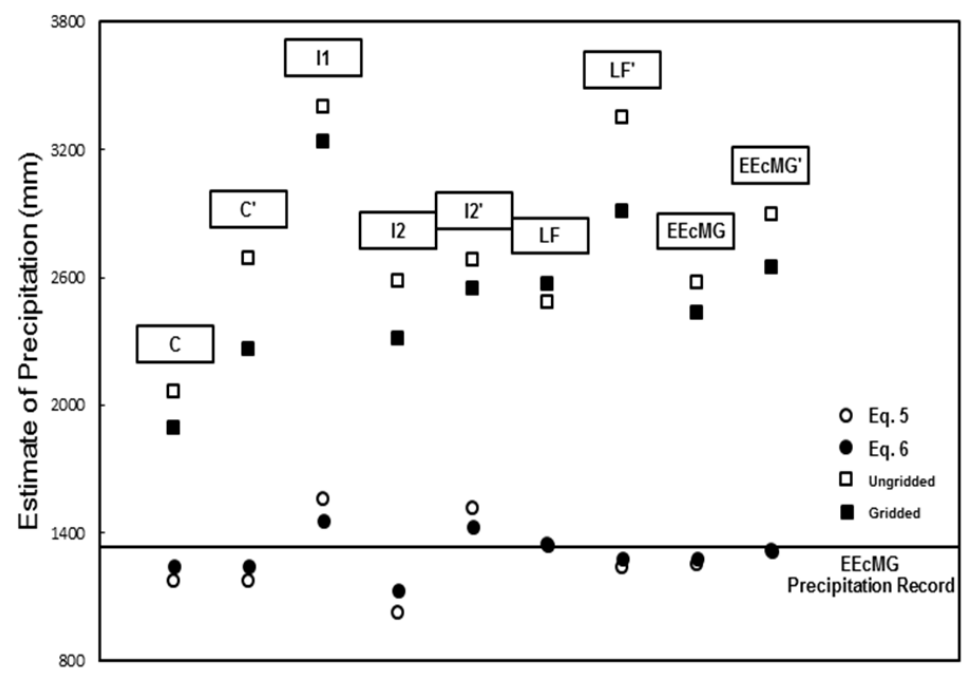

Figura 8 - Estimativas de precipitação para MAP, obtidas dos conjuntos de folhas coletados e da combinação dos dados de cada um dos ambientes selecionados

\section{DISCUSSÃO}

A dinâmica das águas subterrâneas em planícies aluvionares está relacionada com o comportamento do rio e zonas permeáveis por onde a água percorre. Assim tanto o aquifero raso quanto o profundo apresentam sentido de fluxo em direção ao rio Mogi Guaçu, situado a oeste das áreas estudadas. Localmente, a dinâmica das águas subterrâneas nas duas áreas apresenta sentido de fluxo para os meandros dos rios e lagos (caráter efluente) durante o ano de monitoramento. Esses meandros, que secam durante a estação menos chuvosa, também são caminhos de fluxo preferencial das águas em subsuperfície. Os sistemas de fluxo das águas subterrâneas são controlados pelas estruturas deposicionais dos sedimentos, declividade e altos valores de condutividade hidráulica (Woessner, 2000). Na Ilha do Fundão, o fluxo das águas subterrâneas do aquifero raso apresenta direção ao lago existente a oeste da área e ao rio Mogi Guaçu. Na porção mais profunda do aquifero na Ilha do Fundão o gradiente hidráulico modifica-se significativamente no período menos chuvoso (outubro de 2012), porém o sentido geral é para o rio. De acordo com os modelos conceituais de Vidon and Hill (2004), as áreas de estudo, principalmente a Ilha do Fundão, apresenta pequena declividade. O gradiente hidráulico não se modifica significantemente durante o ano, porém próximo as margens do corpo de água há mudança no sentido de fluxo. As áreas de estudo apresentam águas subterrâneas de baixo tempo de residência, e consequentemente as águas são de baixa mineralização, $\mathrm{pH}$ ácido e situados em ambiente oxidante. Os altos valores de condutividade hidráulica favorecem essas características físico-químicas, que possui influência das recargas de águas de chuva como também dos corpos de água existentes; os paleocanais existentes nas 
planícies, em contato com meandros ativos se tornam caminhos de fluxos preferenciais de água subterrânea dos aquíferos rasos (Sophocleous, 2002). Nas porções mais profundas do aquifero há uma maior mineralização das águas e aumento do $\mathrm{pH}$ e o ambiente se torna menos oxidante, indicando um maior tempo de residência e maior isolamento das porções mais superficiais das águas desse aquifero. $\mathrm{Na}$ Ilha do Fundão, a espessura do aquifero poroso é mais espesso, e foi possível analisar o comportamento de dois níveis do aquifero; o nível de água é mais profundo (acima de 7 metros, média de 13 metros); e a porção intermediária (acima de 7,91metros, e média de profundidade de 13 metros); as águas são bicarbonatadas cálcicas, sendo que as águas do aquifero intermediário apresentam maior mineralização.

As estimativas da temperatura com base nas equações do LMA para todos os conjuntos de amostras estudadas mostram um erro em media de $1.6^{\circ} \mathrm{C}$ y $3.1^{\circ} \mathrm{C}$ (Tabela 4), que se encontra por baixo do erro associado ao LMA, que pelo geral é de $\pm 5^{\circ} \mathrm{C}$ (Peppe et al. 2011; Royer, 2012). Os erros obtidos pelas Eq. 4 y Eq. 5 tanto para as assembleias dos diques como para os bancas internas dos meandros se encontram entre $1.6^{\circ} \mathrm{C}$ y $2.1^{\circ} \mathrm{C}$ (Tabela 4), muito próximos ao erro apresentado pelas equações regionais calculadas com base LMA de $\pm 2{ }^{\circ} \mathrm{C}$ (Royer, 2012). A Eq. 4 e a Eq. 5 mostraram um erro médio de $0.8^{\circ} \mathrm{C}$ e de $0.7^{\circ} \mathrm{C}$, ao serem avaliadas em tipos diferentes unidades de vegetação como os biomas Cerrado e Mata Atlântica, e a transição entre ambos (Fanton, 2013) inferiores aos aqui obtidos. A Eq. 5 é a mais precisa para o calculo da temperatura (Tabela 4, Figura 7), como também fora comprovado por outros autores (Hinojosa et al. 2011; Fanton, 2013) que as aplicaram para florestas tropicais e austrais da América do Sul. Os conjuntos de amostras provenientes dos diques marginais de rio e associadas ao Cerrado na área estudada refletem melhor a temperatura quando utilizadas as equações baseadas no LMA. Burnham et al. (2001) atribui esse fato a procedência das folhas, uma vez que as plantas lenhosas que habitam próximas aos curso de agua e lagos tendem a subestimar a MAT entre $2.5^{\circ} \mathrm{C}$ e $5^{\circ} \mathrm{C}$. De forma contraria os bosque com dossel fechado proporcionam estimativas muito precisas. Os valores da temperatura resultantes da aplicação dos dados do CLAMP para os conjuntos de folhas coletados em ambas as posições geomorfológicas estudadas na EEMG mostram um erro que oscila entre $1.8^{\circ} \mathrm{C}$ e $3.9^{\circ} \mathrm{C}$, esse erro se é inferior ao erro associado e similar ao do LMA ( $\pm 5^{\circ} \mathrm{C}$; Royer, 2012$)$, e próximo ao erro mostrado em florestas tropicais $\left( \pm 3{ }^{\circ} \mathrm{C}\right.$; Burnham et al. 2005), apesar desses últimos conjuntos de dados não serem considerados relevantes para a estimação de variáveis climáticas de florestas tropicais ou locais no hemisfério sul, uma vez que ainda são necessários mais dados para calibrar as equações em regiões tropicais e sub-tropicais (Steart et al. 2010; Yang et al. 2011). O conjunto dados Gridded é o que melhor indica a temperatura tanto para as amostras coletadas nos diques quanto para aquelas coletadas nas curvaturas internas de meandros, com um erro médio entre $1.8^{\circ} \mathrm{C}$ e $2.4^{\circ} \mathrm{C}$, o que esta próximo do erro médio do conjunto dados Gridded que é de $\pm 2.1^{\circ} \mathrm{C}$ 
(http://clamp.ibcas.ac.cn/Clampset2.html). Ao fazer as estimativas com as bases de dados CLAMP, observamos que que as amostras dos levees são as que melhor indicam a temperatura.

Os valores de MAP obtidos com o LAA (Eq. 6 e Eq. 7) mostram um média de erro entre -66 mm e $-20 \mathrm{~mm}$ (Tabela 4) que são inferiores aos erros associados com o LAA, de oscilam entre \pm $500 \mathrm{~mm}$ (Wilf et al. 1998) a $\pm 1000 \mathrm{~mm}$ (Peppe et al 2011). As amostras coletadas nas curvaturas internas de meandros mostram melhor a precipitação quando realizadas as predições utilizando as equações baseadas no LAA, uma vez que representam um erro ao redor de -20 y $-23 \mathrm{~mm}$. Por outro lado, para as amostras oriundas dos diques o erro foi de -49 e $-66 \mathrm{~mm}$, se mostrando a Eq. 7 a mais precisa. Essa pequena diferença da precipitação entre ambos ambientes pode ser produto da temperatura, do tipo de solo associado ou influencia da água subterrânea (Royer, 2012). As estimativas da MAP utilizando dos conjuntos de dados CLAMP sobrestimaram constantemente o valor da precipitação, tanto para os conjuntos de folhas coletadas nos diques quanto para as folhas dos das curvaturas internas dos meandros, essa tendência anteriormente tenha sido observada por Wilf et al. (1998). Nesse sentido, autores como (Burnham et al. (2005) tenham relatados que a MAP em florestas tropicais pode ser subestimada com erros superiores aos $400 \mathrm{~mm}$.

\section{CONCLUSÃO}

O Cerrado reflete uma região com clima tropical (quente e sazonal). A média de temperatura está entre $20,5^{\circ} \mathrm{C}$ a $22,5^{\circ} \mathrm{C}$ com poucas mudanças e alta media de precipitação anual, mas concentrada em certos meses do ano. Nos diques marginais, a floresta reflete a temperatura acuradamente, mas não a chuva. Uma linha de tendência pode ser explicada pela influência da água subterrânea, tipo de solo e temperatura. A existência de árvores com sistema de raízes bem desenvolvidas é capaz de alcançar a água subterrânea, cujas profundidades podem variar de 4 a 16 metros de profundidade. Na curvatura interna do meandro, as assembleias de folhas refletem melhor as chuvas que a temperatura, desde que este parâmetro possa ser mudado pela proximidade dos corpos de água (descarga de água subterrânea e proximidade do rio ou meandro). As águas subterrâneas promove também a preservação da matéria orgânica, pois a composição química das águas preservam a biomassa vegetal. Por fim as abordagens integradas e multidisciplinares são importantes ferramentais para os estudos do ambiente moderno e passado, que pode induzir a preservação ou não de assinaturas ambientais de registros passados. 


\section{AGRADECIMENTOS}

Os autores agradecem a Fapesp pelo auxílio a pesquisa (processos 2010/20379-6 e 2013/22729-2), bem como a colaboração do Instituto Florestal do Estado de São Paulo, a CAPES pela bolsa de estudo.

\section{REFERENCIAS BIBLIOGRÁFICAS}

AGUIAR, L.M.S., Camargo A.J.A. 2004. Cerrado: ecologia e caracterização. Planaltina-DF/: Embrapa cerrados, Brasília.

BARBERI M., Salgado-Labouriau, M.L., Suguio K., Martin L., Turq B. 2000. Paleovegetation and Paleoclimate of "Vereda de Águas Emendadas", DF, Central do Brazil. J.S. Am. Earth Sci., 13:241-254.

BURK, D., Uhl, D., and Walter, H. 2005. Some aspects of the actuotaphonomy of leaves in stagnant ponds with implications for the formation of fossil leaf deposits-Preliminary results: Neues

BURNHAM, R.J. 1994. Patterns in tropical leaf litter and implications for angiosperm paleobotany. Review of Palaeobotany and Palynology 81:99-113. doi: http://dx.doi.org/10.1016/0034-6667 (94) 90129-5

BURNHAM, R.J., Ellis, B., Johnson, K.R. 2005. Modern tropical forest taphonomy: Does high biodiversity affect paleoclimatic interpretations? PALAIOS 20:439-451.

BURNHAM, R.J., Pitman, N.C.A., Johnson, K.R., Wilf, P. 2001. Habitat-related error estimating temperatures from leaf margins in a humid tropical forest. Am J Bot 88(6):1096-1102. doi: $10.2307 / 2657093$

BURNHAM, R.J. 1990. Paleobotanical implications of drifted seeds and fruits from modern mangrove litter, Twin Cays, Belize: PALAIOS, v. 5, p. 364-370.

BURT, T.P., Bates, P.D., Stewart, M.D., Claxton, A.J., Anderson, M.G., Price, D.A. 2002a. Water table fluctuations within the floodplain of the River Severn, England. Journal of Hydrology. 262 (2002): 1-20.

BURT, T.P.; Pinay, G.; Matheson, F.E.; Haycock, N.E.; Butturini, A.; Clement, J.C.; Danielescu, S.; Dowrick, D.J.; Hefting, M.M.; Hillbricht-Ilkowaska, A.; Maitre, V. 2002b. Water table fluctuations in the riparian zone: comparative results from a pan-European experiment. Journal of Hydrology. 265 (2002): 129-148.

CBH-Mogi - Comitê da Bacia Hidrográfica do Rio Mogi Guaçu. 1999. Diagnóstico da Bacia Hidrográfica do Rio Mogi Guaçu - "Relatório Zero", 252 pp. 
CHEN, X. 2007. Hydrologic connections of a stream-aquifer-vegetation zone in south-central Platte River valley, Nebraska. Journal of Hydrology (2007) 333, 554-568.

DENVER MUSEUM OF NATURE \& SCIENCE (2011) Guide to morphotyping fossil floras. http://www.paleobotanyproject.org/morphotyping.aspx . Accessed 20 January 2011.

EITEN, G. 1963. Habitat flora of Fazenda Campininha, São Paulo, Brazil. In: FERRI MG (Coord.). Simpósio sobre o Cerrado. Edgard Blucher e EDUSP, São Paulo, pp 157-202.

ELLIS, B., Daly, D.C., Hickey, L.J., Johnson, K.R., Mitchell, J.D,. Wilf, P., Wing, S.L. 2009. Manual of Leaf Architecture. Cornell University Press, Ithaca, New York.

FAEGRI, K., Iversen, J. 1989. Textbook of Pollen Analysis. John Wiley \& Sons, LTD, Chichester FANTON, J.C.M. 2013. Reconstruindo as florestas tropicais úmidas do Eoceno-Oligoceno do sudeste do Brasil (Bacias de Fonseca e Gandarela, Minas Gerais) com folhas de Fabaceae, Myrtaceae e outras angiospermas: Origens da Mata Atlântica. Tese, Universidade Estadual de Campinas.

GASTALDO, R.A. 1994. The genesis and sedimentation of phytoclasts with examples from coastal environments, in Traverse, A., ed., Sedimentation of Organic Particles: Cambridge University Press, Cambridge, UK, p. 103-127.

GASTALDO, R.A. 2004. The relationship between bedform and log orientation in a Paleogene fluvial channel, Weibelster Basin, Germany: Implication for the use of coarse woody debris for paleocurrent analysis. PALAIOS, v. 19, p. 587-597.

GASTALDO, R.A., and Staub, J.R. 1999. A mechanism to explain the preservation of leaf litter lenses in coals derived from raised mires. Paleogeography, Palaeoclimatology, Palaeoecology, v. 149, p. 1-14.

GASTALDO, R.A., Douglass, D.P., and Mccarroll, S.M. 1987. Origin, characteristics and provenance of plant macrodetritus in a Holocene crevasse splay, Mobile delta, Alabama: PALAIOS, v. 2, p. 229-240.

GOUVEIA, S.E.M., Pessenda L.C.R., Boulet R., Aravena R. \& Scheel-Ybert R. 1999. Isótopos do carbono dos carvões e da matéria orgânica do solo em estudos de mudança de vegetação e clima no Quaternário e da taxa de formação de solos no Estado de São Paulo. Anais da Academia Brasileira de Ciências, 71:969-980. doi:10.1016/0895-9811(96)00007-7

HINOJOSA, L.F., Pérez, F., Gaxiola, A., Sandoval, I. 2011. Historical and phylogenetic constraints on the incidence of entire leaf margins: insights from a new South American model. Global Ecol Biogeogr 20:380-390. doi: 10.1111/j.1466-8238.2010.00595.x

HVORSLEV, M.J. 1951. Time lag and soil permeability in groundwater observations. Waterway Experiment Station, Corps. Of Engineers, U.S.Army, 50pp. Bull. Number 36. 
JACOBS, B.F., Herendeen, P.S. 2004. Eocene dry climated and woodland vegetation in tropical Africa reconstructed from fossil leaves from northern Tanzania. Palaeogeography, Palaeoclimatology, Palaeoecology 213:115-123. doi: 10.1016/j.palaeo.2004.07.007

KOWALSKI, E.A. 2002. Mean annual temperature estimation based on leaf morphology: a test from tropical South America. Palaeogeogr Palaeoclimatol Palaeoecol 188: 141-165. doi: 10.1016/j.gloplacha.2007.07.001.

LAUTZ, L.K.; Siegel, D.I. 2006. Modeling surface and groundwater mixing in the hyporheic zone using MODFLOW and MT3D. Advances In Water Resources 29 (2006) 1618 - 1633.

LEDRU, M.P., Campello R.C., Landim, D., Dominguez, J.M., Martin, L., Mourguiaat P., Sifeddine, A., Turcq, B. 2001. Late-Glacial cooling in Amazonia inferred from pollen at Lagoa do Caçó, Northern Brazil. Quaternary Research, v.55, p.47-56.

PEPPE, D.J., Royer, D.L., Cariglino, B. 2011. Sensitivity of leaf size and shape to climate: global patterns and paleoclimatic applications. New Phytologist 190:724-739. doi: 10.1111/j.14698137.2010.03615.x

PERROTA, M.M., Salvador, E.D., Lopes, R.C., D’ Agostino, L.Z., Peruffo, N., Gomes, S.D., Sachs, L.L.B., Meira, V.T., Garcia, M.G.M., Lacerda Filho, J.V. 2005. Mapa Geológico do Estado de São Paulo, escala 1:750.000. Programa Geologia do Brasil - PGB, CPRM, São Paulo PINTO, M.M., Giudice Neto, J.D., Batista, E.A., Toledo Filho, D.V., Mota, I.S. 1997. Vegetação nativa das unidades de conservação e produção de Mogi Guaçu. In: Coletânea de trabalhos do Congresso Brasileiro de Unidades de Conservação. Secretária do Meio Ambiente do Estado de São Paulo, São Paulo

RASSAM, D.W.; Fellows, C.S.; De Hayr, R.; Hunter, H.; Bloesch, P. 2006. The hydrology of riparian buffer zones: two cases studies in an ephemeral and perennial stream. Journal of Hydrology 325 (2006): 306-324.

RAUNKIAER, C. 1934. The Life Forms of Plants and Statistical Plant Geography. Clarendon Press, Oxford

RIBEIRO, J.F., Walter, B.M.T. 2008. As principais fitofisionomias do Bioma Cerrado. In: Sano SM, De Almeida SP, Ribeiro JF Cerrado: Ecologia e Flora. Embrapa Cerrados.- Brasília, DF: Embrapa Informação tecnológica, v.1, p. 153-212.

ROYER, D.L. 2012. Climate reconstruction from leaf size and shape: new developments and challenges. In: Ivany LC, Huber BT (eds) Reconstructing Earth's Deep-Time Climate. The State of the Art in 2012, Paleontological Society Short Course, November 3, 2012. Paleontological Society Papers 18:195-212.

RUSHTON, K. 2007. Representation in regional models of saturated river-aquifer interaction for gaining/ losing rivers. Journal of Hydrology (2007) 334, 262-281. 
SALGADO-LABOURIAU, M.L. (1997) Late Quaternary Paleoclimate in the savannas of South America. Journal of Quaternary Sciences, 12 (5), 371-379 p.

SCHILLING, K.E. 2007. Water table fluctuations under three riparian land covers, Iowa (USA). Hydrological Processes. 21, 2415-2424. 2007.

SOPHOCLEOUS, M. 2002. Interactions between groundwater and surface water: the state of the science. Hydrogeology Journal .10 (1): 52-67. doi: 10.1007/s10040-001-0170-8.

SOUZA, M.M., Ricardi-Branco, F., Jasper, A., Pessenda, L.C.R. 2013. Evolução Paleoambiental Holocênica no Nordeste do Estado de São Paulo. Revista Brasileira de Paleontologia. 16(2):297308. doi: 10.4072/rbp.2013.2.10

STEART, D.C., Spicer, R.A., Bamford, M.K. 2010. Is southern Africa different? An investigation of the relationship between leaf physiognomy and climate in southern African mesic vegetation. Review of Palaeobotany and Palynology 162:607-620. doi: 10.1016/j.revpalbo.2010.08.002 VIDON, P.F., Hill, A.R. 2004. Landscape controls hydrology of stream riparian zones. Journal of Hydrology 292: 210-228.

WEBB, L.J. 1959. A physiognomic classification of Australian rain forest. Journal of Ecology 47:551-570.

WILF, P. 1997. When are leaves good thermometers? A new case for leaf margin analysis. Paleobiology 23: 373-390

WILF, P., Wing, S.L., Greenwood, D.R., Greenwood, C.L. 1998. Using fossil leaves as paleoprecipitation indicators: An Eocene example. Geology 26: 203-206

WOESSNER, W. 2000. Stream and fluvial plain ground water interactions: rescaling hydrogeologic thought. Groundwater 38: 423 - 429

WOLFE, J.A. 1993. A method of obtaining climatic parameters from leaf assemblages. U.S. Geological Survey Bulletin 2040: 1-71.

YANG, J., Spicer, R.A., Spicer, T.E.V., Li, C.S. 2011. 'CLAMP Online': a new web-based palaeoclimate tool and its application to the terrestrial Paleogene and Neogene of North America. Palaeobio Palaeoenv 91:163-183. doi: 10.1007/s12549-011-0056-2. 